\title{
Pre-treatment serum inflammatory cytokines as survival predictors of patients with nasopharyngeal carcinoma receiving chemoradiotherapy
}

\author{
ADEL F. AL-KHOLY ${ }^{1}$, OMMINEA A. ABDULLAH ${ }^{1}$, MAMDOUH Z. ABADIER ${ }^{1}$, MANAL M. HASSAAN ${ }^{2}$, \\ MOHAMED F. SHINDY ${ }^{3}$, DALIA M. NOR EL-DIEN ${ }^{4}$ and ALI HASANEEN ${ }^{5}$ \\ ${ }^{1}$ Department of Medical Biochemistry, Faculty of Medicine, Benda University, Benha 13511; \\ ${ }^{2}$ Department of Medical Biochemistry, Faculty of Applied Medical Sciences, Cairo 11811; \\ Departments of ${ }^{3}$ Otorhinolaryngology, ${ }^{4}$ Clinical Pathology and ${ }^{5}$ Internal Medicine, \\ Faculty of Medicine, Benha University, Benha 13511, Egypt
}

Received May 31, 2016; Accepted August 10, 2016

DOI: $10.3892 /$ mco.2016.1041

\begin{abstract}
The present study aimed to examine the predictability of pre-treatment serum levels of interleukin (IL)-1 $\beta$, IL-6 and tumor necrosis factor (TNF)- $\alpha$ for determining the outcome of patients with nasopharyngeal carcinoma (NPC) assigned for chemoradiotherapy. A total of 35 patients with NPC were subjected to clinical examination and evaluation of performance status using Karnofsky scoring. Nasopharyngoscopy was performed for evaluation and to obtain a biopsy. Blood samples were obtained pre- and post-treatment for polymerase chain reaction quantitative estimation of Epstein-Barr virus (EBV) DNA plasma load and enzyme-linked immunosorbent assay for estimation of serum cytokines. All patients received chemoradiotherapy and were followed-up for 2 years. Cervical lymphadenopathy and recurrent attacks of epistaxis are the most common presenting symptoms. Treatment significantly decreased pre-treatment plasma EBV DNA load and serum levels of IL- 6 and TNF- $\alpha$, and increased serum IL- $1 \beta$ levels. Clinical staging and EBV DNA plasma load revealed positively significant correlation with pre-treatment serum levels of both IL-6 and TNF- $\alpha$, while revealed negative significant correlation with serum IL-1 $\beta$ levels. The 2 -year survival rate was negatively significantly correlated with pre-treatment levels of IL-6 and TNF- $\alpha$, and EBV DNA viral load, while it was positively significantly correlated with pre-treatment performance
\end{abstract}

Correspondence to: Dr Adel F. Al-Kholy, Department of Medical Biochemistry, Faculty of Medicine, Benda University, Farid Nada Street, Benha 13511, Egypt

E-mail: adel.alkholy@fmed.bu.edu.eg

Abbreviations: NPC, nasopharyngeal carcinoma; IL, interleukin; EBV, Epstein-Barr virus; TNF- $\alpha$, tumor necrosis factor- $\alpha$

Key words: nasopharyngeal carcinoma, inflammatory cytokines, plasma EB viral load, survival rate, chemoradiotherapy scores and serum IL-1 $\beta$ levels. Statistical analyses defined high pre-treatment serum IL-6 levels as a significant specific predictor for high mortality rate. It was demonstrated that NPC was associated with high pre-treatment plasma EBV DNA load and serum cytokines, and chemoradiotherapy significantly reduced these high levels. High pre-treatment serum IL-6 level was a significant specific predictor for high mortality rate. Increased post-treatment serum levels of IL-1 $\beta$ indicated good therapeutic response and most probably a high survival rate.

\section{Introduction}

Nasopharyngeal carcinoma (NPC) is a group of malignant epithelial tumors with different etiopathogeneses and a broad range of histopathological appearances (1). Populations with elevated rates include the natives of Southeast Asia, the natives of the Artic region, and the Arabs of North Africa and parts of the Middle East (2). The well-known excess risk for NPC in North Africa is confirmed, with rates reaching the level of 5.4 in men and 1.9 in women, which are 10-times higher compared with that in Europe (3).

Epstein-Barr virus (EBV) is a ubiquitous, gamma-1 lymphotropic virus linked to NPC (4). Decoy receptor (DcR) 3 was overexpressed in NPC and its higher expression scores were observed in metastatic NPC; suggesting that DcR3 may enhance cell metastatic potential (5).

EBV-infected cells secrete EBV-encoded small RNAs, leading to the induction of type-I interferon and inflammatory cytokines, and subsequent immune activation (6). EBV latent membrane protein (LMP) 1 is an oncogenic protein (7) capable of upregulating IL- $1 \alpha$ and IL- $1 \beta$ secretions from epithelial cells and is positively modulated by TNF- $\alpha$ (8). LMP1-expressing cells exhibited increased rates of haptotactic migration. Extracellular-regulated and mitogen-activated protein kinases (MAPK) may contribute to the oncogenicity of LMP1 through its ability to promote cell motility and enhance the invasive properties of epithelial cells (7).

The present prospective study aimed to determine the predictability of pre-treatment serum levels of IL-1 $1 \beta$, IL-6 
and TNF- $\alpha$ for the outcome of patients with NPC assigned for chemoradiotherapy.

\section{Patients and methods}

Patients. The current multi-center study was performed between May 2011 and December 2015, including 2-year follow-ups. The study protocol was approved by the Local Ethics Committee of Benha University, October 6 University and Tanta University. All enrolled patients or their nearest relatives provided written informed consent agreeing to the methodology for investigations and modalities of therapy prior to enrolment. The study included 35 patients with biopsy confirmed NPC. A total of 10 healthy volunteers were selected from those attending Benha University Blood Bank for blood donation after passing examination protocol for blood donation for being serologically negative for $\mathrm{HCV}, \mathrm{HBsAg}$ and $\mathrm{HIV}$, and with no history of previous infectious mononucleosis, no otorhinolaryngology diseases, recent infection or surgery within the last 3 months as a control for results of laboratory investigations.

Otorhinolaryngological evaluation. Patients were subjected to an assessment of full history, clinical examination with respect to nasopharyngeal region, nasopharyngoscopy and computed tomography and/or magnetic resonance imaging (MRI) to determine the full extent of the local and nodal spread of the tumor. The patients were clinically categorized using tumor-node-metastasis staging, according to the American Joint Committee for Cancer (AJCC) staging (9).

Nasopharyngoscopy was performed under general anesthesia to allow proper visualization, lesion identification and biopsy taking. Using a rigid $0^{\circ}, 30^{\circ}$ sinus endoscope cupped biopsy forceps, the biopsy specimen was obtained, including the marginal adjacent tissue and the tumor itself. Specimens were maintained in prepared preservative and sent for histopathological examination. Pathological findings were graded according to the World Health Organization, which has classified NPC into three categories: i) WHO-1, defined as well-to-moderately differentiated squamous or transitional cell carcinoma with keratin production; ii) WHO-2, which is non-keratinizing carcinoma; iii) WHO-3, which is undifferentiated carcinoma, including lymphoepithelioma (10).

Performance status evaluation. All patients were evaluated for performance status criteria using the Karnofsky performance scale (KPS) (11). Performance status evaluation was performed pre-treatment and 6-months post-treatment for 2 years. Inclusion criteria included pathology proven to be WHO type II-III NPC, stage III/IV according to the AJCC staging criteria, no distant metastasis, an expected lifespan of at least 6 months, KPS score $\geq 70$, neutrophil count $>2 \times 10^{9} / 1$ and platelet count $>100 \times 10^{9} / 1$ prior to treatment, and bilirubin $<1.5 \mathrm{mg} / \mathrm{dl}$, AST/ALT $<2$ times the upper limits of normal, serum creatinine $<1.5 \mathrm{mg} / \mathrm{dl}$ and creatinine clearance rate $>50 \mathrm{ml} / \mathrm{min}$ prior to treatment. The exclusion criteria included previous radiotherapy to the head and neck region, previous surgery in the primary tumor site or neck (unless for diagnostic biopsy), history of malignant tumors or simultaneous multiple tumors, a positive pregnancy test result for women of reproductive age, impaired renal or hepatic functions, diabetes mellitus or cardiac diseases.

Laboratory assessments. Blood samples were collected from patients prior to and following completion of their chemoradiotherapy course. The collected blood samples were divided into two samples.

The first sample was collected in EDTA-containing tubes and the plasma was separated immediately and stored at $-80^{\circ} \mathrm{C}$ until use for polymerase chain reaction (PCR) qualitative identification of EBV DNA and quantitative estimation of EBV DNA plasma load, according to the manufacturer's protocol (12). Briefly, a $200 \mu 1$ aliquot of plasma from each sample was used. The DNA was extracted from the samples using the QIAamp ${ }^{\circledR}$ DNA minikit (Qiagen, Hamburg, Germany). The extracted DNA was quantified and checked for purity using a spectrophotometer (Shimadzu, Kyoto, Japan). Quantification of EBV DNA copies in plasma-derived DNA was performed using the $\mathrm{iCycler}_{\mathrm{iQ}} \mathrm{Q}^{\mathrm{TM}}$ Real Time PCR system (Bio-Rad Laboratories, Hercules, CA, USA). The quality of purified DNA from plasma samples was confirmed by conventional PCR amplification of the human $\beta$-globin gene using the following gene-specific primers: Forward: 5'-AGGAGT GGTGGCTCATGTCT-3' and reverse: 5'-CTCAAGGGATCC TCCCATTT-3'. Primers flanking the BamH1W region (EBV coordinate: $14,649-14,724)$ of the EBV genome and TaqMan ${ }^{\circledR}$ probe (Applied Biosystems, Foster City, CA, USA) directed within this flanked region (EBV coordinate: 14,672-14,698) were reported by Lo et al (12) and were custom-made (Applied Biosystems). An aliquot of $5 \mu \mathrm{l}$ purified DNA isolated from the plasma was used for amplification in a total reaction volume of $50 \mu \mathrm{l}$, which contained the following components: $300 \mathrm{nM}$ each primer, $25 \mathrm{nM}$ TaqMan ${ }^{\circledR}$ probe and TaqMan ${ }^{\circledR}$ PCR reagents. The amplification reaction for each sample and standard was performed in duplicate. The standard curve correlating the viral DNA copy to threshold cycle was constructed by amplifying $5 \mu \mathrm{l}$ aliquots of serially diluted DNA isolated from Namalwa cells that contained 45, 450, 45,000, 100,000 and 450,000 EBV DNA copies $/ \mathrm{ml}$. The fluorescence detection threshold value was set at 10x the mean standard deviation of fluorescence in all reactions. EBV DNA load, expressed as viral copy number/ml of plasma, was determined using the following equation: EBV DNA copy/ml = Q (VE / VA) x 1 / VP. Where $\mathrm{Q}$ is the DNA copy determined from standard curve, $\mathrm{VE}$ is the volume of DNA eluent $(50 \mu \mathrm{l})$, VA is the volume of DNA template amplified (5 $\mu \mathrm{l})$ and VP is the volume of plasma used for DNA extraction $(200 \mu \mathrm{l})$.

The second sample was maintained in a plane container and allowed to clot. The serum was subsequently separated by centrifugation for $10 \mathrm{~min}$ at $1,000 \times \mathrm{g}$ using a refrigerated centrifuge. Serum was removed and stored in pyrogen-free Eppendorf tubes at $-80^{\circ} \mathrm{C}$ until assayed for estimation of serum levels of IL-1 $\beta$ (Quantikine ELISA kit; R\&D Systems, Inc., Minneapolis, MN, USA) (13), IL-6 (Pelikine ${ }^{\mathrm{TM}}$ Inc., Concord, MA, USA) (14) and TNF- $\alpha$ (Pelikine ${ }^{\mathrm{TM}}$ Inc.) (15) using ELISA kits, according to the manufacturer's protocols.

Chemoradiotherapy procedure. All patients were assigned to receive the appropriate chemoradiotherapy at the Nuclear Medicine Department, Cancer Institute, Tanta University 
(Tanta, Egypt). Patients received radiotherapy by the simplified intensity modulated radiotherapy technique to shorten the radiation time in each fraction, with prescription doses of 70 , 66.5/68.25 and 61.25 Gy (in 35 fractions) for high-risk gross tumor volume of primary tumor and metastatic lymph nodes, and clinical target volume, respectively. Patients with low-risk clinical target volume, referred to levels IV and $\mathrm{Vb}$ without metastatic cervical lymph nodes, were radiated with $54 \mathrm{~Gy} / 30$ fractions in the anterior-posterior fields. All patients received neoadjuvant chemotherapy prior to radiotherapy with the TPF regimen (docetaxel $75 \mathrm{mg} / \mathrm{m}^{2}$ and cisplatin $75 \mathrm{mg} / \mathrm{m}^{2}$ on day 1 , and 5 -florouracil at $500 \mathrm{mg} / \mathrm{m}^{2}$ on day 3) on continuous intravenous infusion for $120 \mathrm{~h}$ every 3 weeks for 3 cycles. Complete blood count, liver function and renal function were tested prior to each chemotherapy course, and only patients with a qualifying index were allowed to proceed with the next chemotherapy course. Concurrent chemoradiotherapy was administered following three courses of neoadjuvant chemotherapy. Concurrent chemotherapy consisted of weekly cisplatin $\left(40 \mathrm{mg} / \mathrm{m}^{2}\right)$ during radiotherapy, with a maximum of seven courses (16).

Follow-up. Patients completed their follow-up by attending Otorhinolaryngology ENT and Internal Medicine outpatient clinics every 3 months for 2 years for nasopharyngoscopy and neck palpation and for MRI at 3 months after radiotherapy, then every 6 months. Performance status evaluation was performed 6-monthly following treatment for 2 years.

Statistical analysis. The sample size was calculated using the standard nomogram proposed by Kraemer and Thiemann (17). Considering the increasing frequency of NPC in North Africa (3), a sample size of $>30$ patients was determined to be sufficient to detect a difference at the $5 \%$ significance level and to give the trial $60 \%$ power (18). Sample size and power were recalculated and assured using Power and Sample Size Calculation Software program (version 3.1.2) provided by Department of Biostatistics, Vanderbilt University (Nashville, TN, USA). The obtained data were presented as the mean \pm standard deviation, ranges, numbers and ratios. The results were analyzed using one-way analysis of variance, with post-hoc Tukey HSD test and $\chi^{2}$. Sensitivity and specificity of estimated parameters as survival predictors were evaluated using the receiver operating characteristic (ROC) curve analysis judged by the area under the curve (AUC) compared with the null hypothesis that $\mathrm{AUC}=0.05$. Possible associations were investigated using Spearman linear regression. Statistical analysis was performed using the SPSS (version 15) statistical package for Windows (SPSS, Inc., Chicago, IL, USA). $\mathrm{P}<0.05$ was considered to indicate a statistically significant difference.

\section{Results}

The present study included 35 patients with NPC. Clinical presenting symptoms, clinical stage and pathological grading data are shown in Table I. All patients exhibited a gradual decrease of their performance scores throughout the follow-up period, but the extent of decrease was gradual with non-significant differences $(\mathrm{P}>0.05)$ between patient frequency among higher scoring items at 6 months post-treatment compared
Table I. Enrolled patient data.

\begin{tabular}{lc}
\hline Patient information & Findings \\
\hline Demographic data & \\
Age, years (range) & $54.5 \pm 11.8(37-71)$ \\
Gender (male:female) & $2.18: 1$ \\
Smoking history (\%) & \\
Current & $17(48.6)$ \\
Ex-smoker & $8(22.8)$ \\
Non-smoker & $10(28.6)$ \\
Occupational exposure frequency & $13(37.1)$ \\
Presenting symptoms (\%) & \\
Cervical lymphadenopathy & $23(65.7)$ \\
Recurrent epistaxis & $16(45.7)$ \\
Secretory otitis media & $10(28.6)$ \\
Headache & $9(25.7)$ \\
Otalgia & $7(20)$ \\
Frequency of symptoms (1:2:3:4:5) & $17: 9: 7: 1: 1$ \\
Mean number (range) & $1.86 \pm 1(1-5)$ \\
Clinical stage (Stage II:III:IV) & $13: 13: 9$ \\
Pathological gradinga (Type $1: 2: 3)$ & $15: 12: 8$ \\
\hline
\end{tabular}

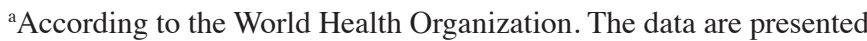
as the mean \pm standard deviation.

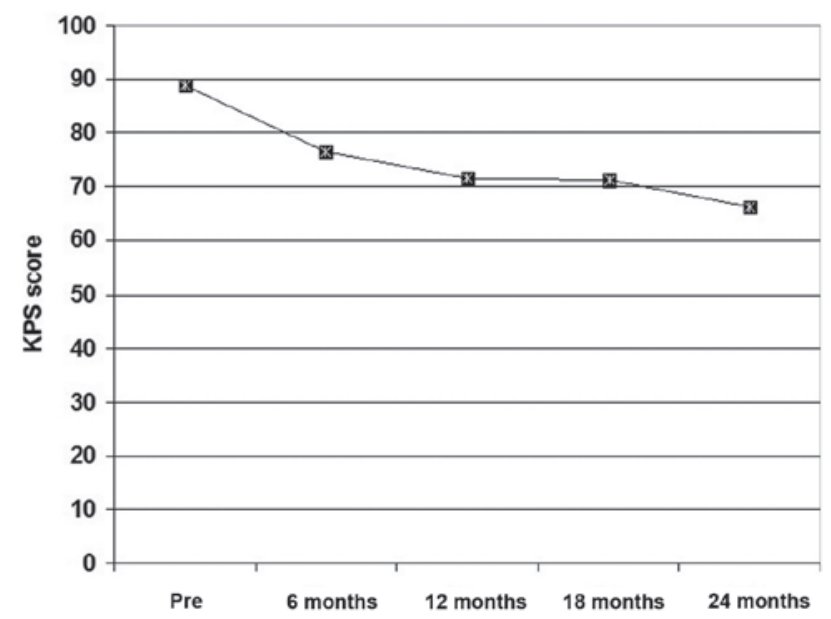

Figure 1. Mean collective KPS determined throughout the 2-year follow up compared with the pre-treatment score. KPS, Karnofsky performance score; Pre, pre-treatment.

with pre-treatment frequency. Thereafter, at 12, 18 and 24 months post-treatment, the frequency of patients with high performance scores was significantly lower compared with the pre-treatment frequency. The mean of collective scoring throughout the follow-up period was significantly lower compared with the pre-treatment collective score (Fig. 1).

The mean pre- and post-treatment serum levels of the investigated cytokines were significantly higher compared with the control levels. The mean post-treatment plasma EBV DNA viral load and serum levels of IL- 6 and TNF- $\alpha$ were 
Table II. Pre- and post-treatment laboratory findings of studied patients compared with control levels.

\begin{tabular}{|c|c|c|c|c|}
\hline \multirow[b]{2}{*}{ Cytokine level } & \multirow[b]{2}{*}{ Control } & \multicolumn{2}{|c|}{ Patients } & \multirow[b]{2}{*}{ P-value } \\
\hline & & Pre-treatment & Post-treatment & \\
\hline Serum IL-1 $\beta, \mathrm{ng} / \mathrm{ml}\left(\mathrm{P}-\right.$ value $\left.^{\mathrm{b}}\right)$ & $1.75 \pm 0.4$ & $2.44 \pm 0.53(0.012)$ & $3.03 \pm 1.1(0.035)$ & 0.001 \\
\hline Serum TNF- $\alpha$, ng/ml (P-value $\left.{ }^{\mathrm{b}}\right)$ & $3.64 \pm 1.17$ & $13.39 \pm 4.51(0.0004)$ & $11.06 \pm 2.71(0.0004)$ & 0.002 \\
\hline Serum IL-6, ng/ml (P-value $\left.{ }^{\mathrm{b}}\right)$ & $13.53 \pm 2.84$ & $189.89 \pm 43.36(0.0001)$ & $35.52 \pm 13.92(0.0003)$ & 0.0001 \\
\hline Plasma EBV DNA load, copies/ml & - & $2,112.11 \pm 595.62$ & $63.93 \pm 27.16$ & 0.0001 \\
\hline
\end{tabular}

${ }^{\mathrm{a} C}$ Comparing pre- and post-treatment levels; ${ }^{\mathrm{b}} \mathrm{Compared}$ with control levels. The data are presented as mean \pm standard deviation. IL, interleukin; TNF, tumor necrosis factor; EBV, Epstein-Barr virus.

significantly lower, but post-treatment serum levels of IL-1 $\beta$ were significantly higher compared with the pre-treatment levels (Table II).

Throughout the 2-years follow-up period, nine patients succumbed to mortality, giving a 2 -year mortality rate of $25.7 \%$. A total of 5 mortalities were associated with radiation-related injuries; 2 patients succumbed to secondary development of mucosal necrosis, 2 due to massive gastrointestinal hemorrhage and 1 secary to development of radiation encephalopathy. A total of 2 mortalities were secondary to local regional therapy failure and another 2 were secondary to distant metastasis.

At end of the 2-year follow-up, collective mortality rates were $44.5,23.1$ and $15.4 \%$ for patients with pre-treatment clinical stage IV, III and II, respectively. The 2-year survival rate demonstrated negative significant correlation with serum levels of IL- 6 and TNF- $\alpha$, and with plasma levels of EBV DNA viral load. It also demonstrated positive significant correlation with serum levels IL-1 $\beta$ and KPS; however, demonstrated positive non-significant correlation with pre-treatment clinical staging. Detailed correlations between the investigated parameters are shown in Table III.

ROC curve analysis defined high pre-treatment serum IL-6, serum TNF- $\alpha$ and plasma EBV DNA as sensitive predictors of mortality, with descending order of significance compared with the null hypothesis of $\mathrm{AUC}=0.5$, while high serum IL- $1 \beta$ as a specific predictor for survival with significantly higher AUC compared with the null hypothesis (Table IV and Fig. 2). Regression analysis defined high pre-treatment serum IL-6 as a specific significant predictor for mortality $(\beta=-0.529$, $\mathrm{t}=3.584, \mathrm{P}=0.001)$.

\section{Discussion}

Clinical presentation of studied cases of NPC was mosaic and non-specific. The major presenting symptoms were cervical lymphadenopathy, epistaxis of unexplained origin and varied otological symptoms and signs. Similarly, Adham et al (19) reported that the initial diagnosis of NPC is difficult to make since early signs and symptoms of NPC are not specific to the disease.

The estimated pre-treatment plasma EB viral DNA load were decreased significantly following the completion of the treatment protocol and demonstrated a positive significant correlation with clinical tumor aggressiveness. These findings indicated a close association between the presence of NPC and EBV viremia, and the probability of reliance on estimation of plasma EBV DNA load as a non-invasive diagnostic modality for NPC that provided a pre-treatment knowledge about disease stage and response to applied therapy.

In line with these data, Ji et al (20) reported that at the cutoff point of 0 copies/ml plasma EBV DNA had a sensitivity, positive and negative predictive values of 86.8, 30 and $99.3 \%$, respectively, for NPC detected within the first year of follow-up. Additionally, it had a sensitivity of 81.5 and $100 \%$ for patients who had early and advanced NPC, respectively. Hutajulu et al (21) documented elevated viral DNA in the patient circulation, as well as nasopharyngeal site underline the role of EBV for NPC development.

In trials to explore the association between NPC and EBV infection, experimental studies using NPC lines infected in vitro with $\mathrm{EBV}$ showed that in vitro $\mathrm{EBV}$ infection resulted in the activation of signal transducer and activator of transcription (STAT)-3 and nuclear factor $-\kappa \mathrm{B}$ signaling cascades in nasopharyngeal epithelial cells. This resulted in increased expression of their downstream targets. These findings suggest that EBV infection may manipulate multiple cellular signaling cascades to protect infected cells from immunological attack and to facilitate cancer development $(22,23)$.

Estimated post-treatment levels of IL- 6 and TNF- $\alpha$ were significantly decreased compared with pre-treatment levels that showed positive significant correlation with clinical staging and EBV DNA plasma load; a finding indicating a close association between NPC and high serum levels of both inflammatory cytokines. The detected association between clinical staging and pre-treatment plasma EBV DNA viral load on one side and pre-treatment serum cytokines was approved experimentally by Zhang et al (24) who reported that EBV-infected nasopharyngeal epithelial cells exhibited enhanced response to IL-6-induced STAT-3 activation through overexpression of the IL-6 receptor, thus promoting growth and invasive properties EBV-positive NPC cells. Ansari et al (25) observed that EBV facilitates its genome persistence and evasion of host immune responses through activation of caspase-1, which cleaves the pro-forms of inflammatory IL-1 $\beta$, IL-18 and IL-33 cytokines. Song et al (26) suggested that TNF- $\alpha$ may be a promoter for NPC local spread and metastasis through the induction of inhibitor of apoptosis proteins, which contribute to both tumor 
Table III. Spearman correlation between various factors.

\begin{tabular}{|c|c|c|c|c|c|c|}
\hline \multirow[b]{2}{*}{ Factor } & \multicolumn{2}{|c|}{ 2-year survival } & \multicolumn{2}{|c|}{ Plasma EBV DNA } & \multicolumn{2}{|c|}{ Clinical staging } \\
\hline & Rho & P-value & Rho & P-value & Rho & P-value \\
\hline Karnofsky performance score & 0.379 & 0.025 & -0.395 & 0.017 & -0.716 & 0.0009 \\
\hline Clinical staging & -0.248 & $>0.05$ & 0.499 & 0.002 & - & - \\
\hline Serum IL-1 $\beta(\mathrm{ng} / \mathrm{ml})$ & 0.415 & 0.013 & -0.425 & 0.011 & -0.555 & 0.001 \\
\hline Serum TNF- $\alpha(\mathrm{ng} / \mathrm{ml})$ & -0.458 & 0.006 & 0.350 & 0.039 & 0.394 & 0.019 \\
\hline Serum IL-6 (ng/ml) & -0.541 & 0.001 & 0.504 & 0.002 & 0.806 & 0.0004 \\
\hline Plasma EBV DNA (copies/ml) & -0.401 & 0.017 & - & - & - & - \\
\hline
\end{tabular}

IL, interleukin; TNF, tumor necrosis factor; EBV, Epstein-Barr virus.

Table IV. Receiver operating characteristic curve analysis of clinical staging and laboratory findings as predictors for 2-year survival determined by AUC.

\begin{tabular}{lcrrr}
\hline Factor & AUC & SE & P-value & 95\% CI \\
\hline Clinical stage & 0.346 & 0.109 & $>0.05$ & $0.132-0.560$ \\
Serum IL-1 $\beta(\mathrm{ng} / \mathrm{ml})$ & 0.774 & 0.085 & 0.016 & $0.607-0.940$ \\
Serum TNF- $\alpha(\mathrm{ng} / \mathrm{ml})$ & 0.199 & 0.105 & 0.008 & $-0.007-0.405$ \\
Serum IL-6 $(\mathrm{ng} / \mathrm{ml})$ & 0.143 & 0.076 & 0.002 & $-0.005-0.291$ \\
Plasma EBV DNA load (copies/ml) & 0.235 & 0.106 & 0.019 & $0.028-0.442$ \\
\hline
\end{tabular}

AUC, area under curve; SE, standard error; CI, confidence interval; IL, interleukin; TNF, tumor necrosis factor; EBV, Epstein-Barr virus.

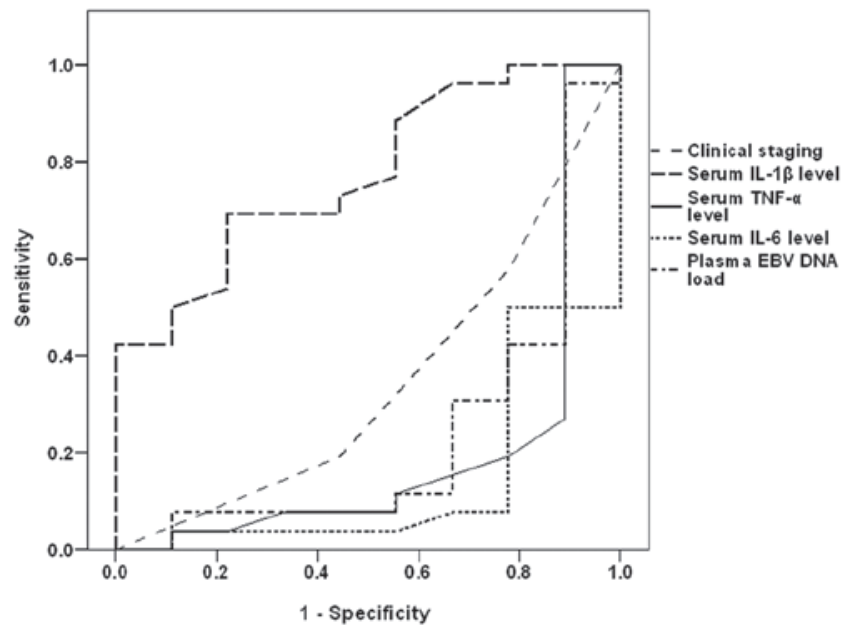

Figure 2. Receiver operating characteristic curve analysis of the clinical staging and pre-treatment laboratory data as predictors for the 2-year survival.

progression and tumor metastasis. Liao et al (27) used NPC cell lines to detect that IL-6 promoted NPC cell proliferation in a dose- and time-dependent manner, and this was accompanied by increasing cyclin D1 and Bcl-2 expression, STAT-3 activation, and inhibition of Bax and p21 expression. Liu et al (28) observed that in certain macrophages of the tumor stroma of NPC tissue, IL-6- and TNF- $\alpha$-dependent expression of tryptophan-catabolizing enzyme indoleamine 2,3-dioxygenase led to suppressed proliferation of $\mathrm{T}$ cells and impaired cytotoxic activity of CD8(+) T cells, thus facilitating immune escape.

Notably, the estimated pre-treatment levels of IL-1 $\beta$ were significantly lower compared with post-treatment levels and had negative significant correlation with clinical staging and plasma EBV DNA viral load. These data may indicate an abnormal behavior of IL-1 $\beta$, which despite being an inflammatory cytokine, appears to have anticancer action. In line with these findings, Chen et al (29) experimentally reported that tumor inflammasomes, which are critical for IL-1 $\beta$ production, serve a key role in tumor control by recruiting neutrophils, and their expression levels manifested by increased levels of IL-1 $\beta$ are favorable prognostic markers and promising therapeutic targets in patients.

The reported 2-year survival rate demonstrated negative significant correlation with pre-treatment serum levels of IL-6 and TNF- $\alpha$, while showed positive significant correlation with pre-treatment serum level of IL-1 $\beta$. Statistical analyses defined high pre-treatment serum IL- 6 as a significant specific predictor for high mortality rate. These findings go in hand with Lu et al (30) who reported that pre-treatment serum levels of IL- 2 and TNF- $\alpha$ were closely associated with the overall survival of patients with NPC, with $>2$-fold increase in the risk of mortality in patients with low IL-2 expression and/or high TNF- $\alpha$ expression compared with those with high IL-2 or low TNF- $\alpha$ levels. Visconti et al (31) demonstrated that elevated IL-6 and IL-10 levels appear to be independently associated with worse prognosis in terms of overall and disease-free survival in cancer patients. Reitter et al (32) reported that 
elevated levels of IL-6, IL-8 and IL-11 were associated with worse survival of cancer patients. Cheng et al (33) revealed that NPC patients who had high IL-8 levels had significantly shorter overall survival and disease-free survival.

In conclusion, NPC is associated with high pre-treatment plasma EBV DNA load and serum cytokines, and chemoradiotherapy significantly reduced these high levels. High pre-treatment serum IL-6 level is a significantly specific predictor for high mortality rate. Increased post-treatment serum levels of IL-1 $\beta$ indicated good therapeutic response and most probably high survival rate.

\section{Acknowledgements}

The authors would like to thank staff members, assistants, technicians and workers at Tanta Cancer Institute for providing assistance for researchers and patients during the chemoradiotherapy.

\section{References}

1. Petersson F: Nasopharyngeal carcinoma: A review. Semin Diagn Pathol 32: 54-73, 2015.

2. Yu MC and Yuan JM: Epidemiology of nasopharyngeal carcinoma. Semin Cancer Biol 12: 421-429, 2002.

3. Zanetti R, Tazi MA and Rosso S: New data tells us more about cancer incidence in North Africa. Eur J Cancer 46: 462-466, 2010.

4. Chang CM, Yu KJ, Mbulaiteye SM, Hildesheim A and Bhatia K: The extent of genetic diversity of Epstein-Barr virus and its geographic and disease patterns: A need for reappraisal. Virus Res 143: 209-221, 2009.

5. Ho CH, Chen CL, Li WY and Chen CJ: Decoy receptor 3 , upregulated by Epstein-Barr virus latent membrane protein 1, enhances nasopharyngeal carcinoma cell migration and invasion. Carcinogenesis 30: 1443-1451, 2009.

6. Iwakiri D and Takada K: Role of EBERs in the pathogenesis of EBV infection. Adv Cancer Res 107: 119-136, 2010.

7. Dawson CW, Laverick L, Morris MA, Tramoutanis G and Young LS: Epstein-Barr virus-encoded LMP1 regulates epithelial cell motility and invasion via the ERK-MAPK pathway. J Virol 82: 3654-3664, 2008.

8. Huang YT, Liu MY, Tsai CH and Yeh TH: Upregulation of interleukin-1 by Epstein-Barr virus latent membrane protein 1 and its possible role in nasopharyngeal carcinoma cell growth. Head Neck 32: 869-876, 2010.

9. AJCC. Larynx. In: American Joint Committee on Cancer. AJCC Cancer Staging Manual. 6th edition. Springer, New York, pp47-57, 2002.

10. Shanmugaratnam KS and Sobin LH: Histological typing of upper respiratory tract tumors. Geneva: World Health Organization, 1978.

11. Schag CC, Heinrich RL and Ganz PA: Karnofsky performance status revisited: Reliability, validity, and guidelines. J Clin Oncol 2: 187-193, 1984

12. Lo YM, Chan LY and Lo KW: Quantitative analysis of cell-free Epstein-Barr virus DNA in plasma of patients with nasopharyngeal carcinoma. Cancer Res 59: 1188-1191, 1999.

13. Dinarello CA: ELISA kits based on monoclonal antibodies do not measure total IL-1beta synthesis. J Immunol Methods 148: 255-259, 1992

14. Gaines-Das RE and Poole S: The international standard for interleukin-6. Evaluation in an international collaborative study. J Immunol Methods 160: 147-153, 1993.

15. De Kossodo S, Houba V and Grau GE: Assaying tumor necrosis factor concentrations in human serum. A WHO international collaborative study. J Immunol Methods 182: 107-114, 1995.
16. Kong L, Zhang YW,Hu CS and Guo Y: Neoadjuvant chemotherapy followed by concurrent chemo-radiation for locally advanced nasopharyngeal carcinoma. Chin J Cancer 29: 551-555, 2010.

17. Kraemer HC and Theimann S: How many subjects? Statistical Power Analysis in Research. Newbury Park, CA: Sage, 1987.

18. Murphy KR and Myors B: Statistical power analysis: A simple and general model for traditional and modern hypothesis tests. 2nd edition, Lawrence Erlbaum Associates, Inc., 2003.

19. Adham M, Kurniawan AN, Muhtadi AI, Roezin A, Hermani B, Gondhowiardjo S, Tan IB and Middeldorp JM: Nasopharyngeal carcinoma in Indonesia: Epidemiology, incidence, signs, and symptoms at presentation. Chin J Cancer 31: 185-196, 2012.

20. Ji MF, Huang QH, Yu X, Liu Z, Li X, Zhang LF, Wang P, Xie SH, Rao HL, Fang F, et al: Evaluation of plasma Epstein-Barr virus DNA load to distinguish nasopharyngeal carcinoma patients from healthy high-risk populations in Southern China. Cancer 120: 1353-1360, 2014.

21. Hutajulu SH, Kurnianda J, Tan IB and Middeldorp JM: Therapeutic implications of Epstein-Barr virus infection for the treatment of nasopharyngeal carcinoma. Ther Clin Risk Manag 10: 721-736, 2014.

22. Stewart S, Dawson CW, Takada K, Curnow J, Moody CA, Sixbey JW and Young LS: Epstein-Barr virus-encoded LMP2A regulates viral and cellular gene expression by modulation of the NF-kappaB transcription factor pathway. Proc Natl Acad Sci USA 101: 15730-15735, 2004.

23. Lo AK, Lo KW, Tsao SW, Wong HL, Hui JW, To KF, Hayward DS, Chui YL, Lau YL, Takada K and Huang DP: Epstein-Barr virus infection alters cellular signal cascades in human nasopharyngeal epithelial cells. Neoplasia 8: 173-180, 2006.

24. Zhang G, Tsang CM, Deng W, Yip YL, Lui VW, Wong SC, Cheung AL, Hau PM, Zeng M, Lung ML, et al: Enhanced IL-6/IL-6R signaling promotes growth and malignant properties in EBV-infected premalignant and cancerous nasopharyngeal epithelial cells. PLoS One 8: e62284, 2013.

25. Ansari MA, Singh VV, Dutta S, Veettil MV, Dutta D, Chikoti L, Lu J, Everly D and Chandran B: Constitutive interferon-inducible protein 16-inflammasome activation during Epstein-Barr virus latency I, II and, III in B and epithelial cells. J Virol 87: 8606-8623, 2013.

26. Song Q, Wang G, Chu Y, Zhou L, Jiang M, He Q, Liu M, Qin J and Hu J: TNF- $\alpha$ up-regulates cellular inhibitor of apoptosis protein 2 (c-IAP2) via c-Jun N-terminal kinase (JNK) pathway in nasopharyngeal carcinoma. Int Immunopharmacol 16: 148-153, 2013.

27. Liao Q, Zeng Z, Guo X, Li X, Wei F, Zhang W, Li X, Chen P, Liang F, Xiang B, et al: LPLUNC1 suppresses IL-6-induced nasopharyngeal carcinoma cell proliferation via inhibiting the Stat3 activation. Oncogene 33: 2098-2109, 2014.

28. Liu WL, Lin YH, Xiao H, Xing S, Chen H, Chi PD and Zhang G: Epstein-Barr virus infection induces indoleamine 2,3-dioxygenase expression in human monocyte-derived macrophages through $\mathrm{p} 38 /$ mitogen-activated protein kinase and NF- $\mathrm{BB}$ pathways: Impairment in T cell functions. J Virol 88: 6660-6671, 2014.

29. Chen LC, Wang LJ, Tsang NM, Ojcius DM, Chen CC, Ouyang CN, Hsueh C, Liang Y, Chang KP, Chen CC and Chang YS: Tumor inflammasome-derived IL- $1 \beta$ recruits neutrophils and improves local recurrence-free survival in EBV-induced nasopharyngeal carcinoma. EMBO Mol Med 4: 1276-1293, 2012.

30. Lu K, Feng X, Deng Q, Sheng L, Liu P, Xu S and Su D: Prognostic role of serum cytokines in patients with nasopharyngeal carcinoma. Onkologie 35: 494-498, 2012.

31. Visconti L, Nelissen K, Deckx L, van den Akker M, Adriaensen W, Daniels L, Matheï C, Linsen L, Hellings N, Stinissen P and Buntinx F: Prognostic value of circulating cytokines on overall survival and disease-free survival in cancer patients. Biomark Med 8: 297-306, 2014.

32. Reitter EM, Ay C, Kaider A, Pirker R, Zielinski C, Zlabinger G and Pabinger I: Interleukin levels and their potential association with venous thromboembolism and survival in cancer patients. Clin Exp Immunol 177: 253-260, 2014.

33. Cheng D, Kong H and Li Y: Prognostic value of interleukin-8 and MMP-9 in nasopharyngeal carcinoma. Eur Arch Otorhinolaryngol 271: 503-509, 2014. 